\title{
A concept mobility device with multi-positional configurations and child-kind restraint for safe perioperative transfer and induction of anaesthesia in children with autistic spectrum disorder - a cross sectional study
}

Hwan Ing Hee ( $\nabla$ hee.hwan.ing@singhealth.com.sg )

Duke NUS Graduate Medical School

Ying Ching Lim

Khoo Teck Puat Hospital

Tracy Tan

Duke NUS Graduate Medical School

Sharon Wan

Duke NUS Graduate Medical School

Olivia Wijeweera

Duke NUS Graduate Medical School

Sumin Lee

Duke NUS Graduate Medical School

Kavitha Raghavan

St. Jude Children's Research Hospital

\section{Research Article}

Keywords: Autistic spectrum disorder, Perioperative movement, Perioperative transport, Hospital mobility device, Induction of Anaesthesia

Posted Date: December 1st, 2020

DOl: https://doi.org/10.21203/rs.3.rs-113736/v1

License: (c) (1) This work is licensed under a Creative Commons Attribution 4.0 International License.

Read Full License

Version of Record: A version of this preprint was published at BMC Health Services Research on April 9th, 2021. See the published version at https://doi.org/10.1186/s12913-021-06309-3. 


\section{Abstract}

Background : Transfer into operating room, onto operating table and mask induction of anaesthesia are major challenge faced by children with Autistic Spectrum Disease (ASD). In a pilot study, parents observed that perioperative transfer becomes unsafe and difficult when children with ASD becomes uncooperative.

Method: A CHILD-KIND CONCEPT mobility system comprising of multi-positioning seat configurations and restraining module was developed with inputs from multi-disciplinary healthcare professionals and parents with children with ASD. To appeal to children and motivate child-machine interaction, the seat configurations and restraining module are designed to take the form of child-friendly, non-threatening, fun and familiar items. The sitting configuration, sitting to supine transformation, the restraint modules resemble racing-car seat, reclining motion of a home massage chair, safety restraints found in airplanes and amusement rides respectively. Healthcare professionals (HCP) involved in the perioperative patient care, parents of ASD children and children (neurotypical and ASD) experience the use of the system in a non-clinical environment and participated in a survey study. The acceptance of its functionality (HCP, parents) for perioperative transfer and induction of anaesthesia, rating of the user experience and likes and dislikes of (parents and children) were obtained.

Results: Thirty-two HCP, 30 parents and 23 children participated. Majority of parents and HCP opined the use of the system enables improvement in the management of perioperative movement $(90.0 \%$ parents, $100 \% \mathrm{HCP}$ ), safe perioperative movement ( $86.7 \%$ parents, $96.9 \% \mathrm{HCP}$ ) and promotes ease of anaesthesia induction (76.7\% parents, $90.6 \% \mathrm{HCP}$ ) for uncooperative combative ASD children. Overall, $90.6 \% \mathrm{HCP}$ and $76.7 \%$ of parents would recommend its frequent use in their own practice and their ASD children respectively; $93.8 \% \mathrm{HCP}$ and $86.7 \%$ parents would recommend it to other HCP and parents for use in other ASD children. Attractiveness and multi-functionality are attributes endorsed by parents and children. Children endorse its use for induction of anaesthesia (73.9\%), dental chair (82.6\%), intra-hospital transfer (95.7\%).

Conclusion : A child-kind mobility device that integrates appeal with functionality of restraint and multipositional transformation has a potential to promote safe perioperative movement and ease of induction of anaesthesia in anxious uncooperative ASD children.

\section{Trial registration : None}

\section{Introduction}

Autistic Spectrum Disorder (ASD) is a heterogenous neurodevelopmental disorder [1,2] characterized by deficiencies in social skills, language development, restrictive interest and inability to cope with a change from routine. Children with ASD also have anxiety disorders and sensory hypersensitivities [3, 4]. Many also have impairment in motor development $[4,5,6]$, these mobility needs are often unrecognized [7]. 
Perioperative hospital visit is a stressful experience for these children for several reasons. Operating theatre (OT) environment presents multiple sensory stimuli such as unfamiliar crowd, lights, noises for children with sensory hypersensitivities. Routine activities embedded in admission processes such as waiting, clinical parameter measurements and patient transfers to the OT and operating room (OR) adds further stress. Movement onto the OT table and placement of face mask during induction of anaesthesia are have been identified as perioperative challenges [8]. When children are overtly anxious and agitated, they respond with a meltdown behaviour that may manifest as 'flight', 'fight' or even self-harm.

There is growing recognition within community, schools, hospitals [3] to support the needs of children with ASD. In recent years, policy statements have been established to promote road safety for safe transportation of children with special needs $[9,10]$. There is limited work in literature related to perioperative transfer and safety. In our pilot study, parents of ASD children observed that perioperative transfer becomes unsafe and difficult when children becomes uncooperative. We developed a concept specialized child-kind mobility device in an attempt to meet the mobility needs of ASD children $[11,12]$. The goal is to enhance safe and efficient process in (a) moving child to the OR (b) facilitate induction of anaesthesia and (c) transfer of anaesthetised children onto the operating table. We hypothesize that a child-kind approach by appealing to child's perception of fun and familiarity will motivate better childmachine interaction, thereby facilitating the performance of the function of the mobility device.

The primary aim of this study is to evaluate healthcare providers (HCP) and parents' opinion on the potential functionality of the proposed mobility system for safe restraint for induction of anaesthesia and transfer of children in the OR. The secondary aim is to evaluate the general experience of such a system by parents and children.

\section{Methodology}

This is a prospective cross-sectional observation and survey study conducted with institutional ethics review board approval (SingHealth CIRB 2017/3127) and informed consent between April 2018 to November 2019. The study complies with the standards, guidelines and regulations for clinical research.

\section{Specialized design Mobility equipment}

A specialized mobility system (I-MOVE) is developed as a CONCEPT CHILD-KIND MOBILITY DEVICE to interest children and initiate child-machine interaction that includes sitting on it in the 'chair mode', selfapplication of the restraint module and assisted ambulation [12]. See Figure 1. This was developed as a collaboration between investigators from the paediatric anaesthesia department and biomedical engineers with input from parents with ASD children as well as multi-disciplinary healthcare professionals with experience in the care of children with ASD [12]. The mobility system is a multiposition configuration mobile chair-bed system with a restraining module [12,13]. These positions are 'sitting' for preoperative sedation and induction of anaesthesia, 'supine' for airway management and transfer, 'lateral tilt' to aid lateral transfer onto the OT table, 'Trendelenburg' for oropharyngeal suctioning as part of airway protection [12]. These movements were activated via hand-held remote. In the resting 
position, it resembles a racing car chair, transformation to supine position resembles a reclining massage chair, all of which are different forms of chairs children are familiar with.

The restraint module is a key feature and comes in 3 options [12]; an over the hip adjustable restraint (like an airplane seat belt), an overhead restraint ('amusement park restraint-like') or a combination of the two with the strap traversing through the overhead restraint. The amusement park design adds to the contextual fun-based approach to I-MOVE. This reduces manpower and physical restraint used to move patients into the $\mathrm{OR}$, patient handling and lifting transferring.

\section{Survey participants and method}

Survey participants include healthcare providers (HCP), parents and children. The inclusion criteria are $\mathrm{HCP}$ with experience in the perioperative care of ASD children in the operating theatre. The inclusion criteria for parents are those with children diagnosed with ASD. The exclusion criteria were permanent staff of paediatric anaesthesia department to avoid conflict of interest.

The inclusion criteria for children participants are neurotypical children or ASD children between 6 to 16 years old and whom parents have confidence of ability to complete the survey independently. Exclusion criteria are children with uncontrolled disruptive behaviour.

Informed consent was obtained from HCP and parents. Parental consent was obtained for children with further assent obtained from children as deemed appropriate.

\section{Procedure}

Parents and children were introduced to the operating theatre waiting area and the hospital trolley. The rest of the study was performed in a dedicated hospital room where I-MOVE was located and participants were informed about the motivation for development of the I-MOVE. The stage of Proof of concept of IMOVE was emphasized. For the children, I-MOVE was introduced as a 'special chair concept' to help children move around in the hospital and to 'go to sleep'. This was followed by a demonstration of the operation and function of I-MOVE in all configurations. HCP and parents were instructed to examine and operate the system. Children were invited to explore the I-move such as sit on it and putting on the restraint module. This is followed by a survey.

\section{Questionnaire Measures}

In the survey, HCP and parents answered eight closed ended 7-points Likert questions which evaluate their acceptance of multiple functions of I-move on anxious and uncooperative ASD children based on their work experience (HCP) and personal experience (parents). Parents and children rated their general experience of the special chair using 5 points Likert scale and explained their likes and dislikes.

Parents were asked on their opinion on the suitability of use of I-move and restraint in various situations. Children indicated the situations in which they would use the I-move. 


\section{Statistics}

Frequency was presented as numbers and percentage. For data analysis, methods used were t test for continuous data and chi square test for dichotomous data using SPSS version 19 (Inc Chicago IL, US). A $p$ value of less than 0.05 was considered statistical significance.

In a previous observation survey, we found that $25 \%$ of parents would use the traditional hospital mobility device such as hospital trolley and wheelchairs. Parental opinion was used in the sample size calculation as parents of ASD children are the best resource to create a successful experience for their children [8]. We hypothesize that if the specially designed mobility device could garner a $75 \%$ agreement for use as a perioperative special mobility device, at a power of 0.9, 23 participants were needed for the parent expert group. Hence a minimum of 23 was recruited for the parent and expert groups.

\section{Results}

Thirty-two healthcare professionals, 30 parents of ASD children and 23 children took part in the study. Of the 23 children, 14 had ASD. The demographic baseline characteristics is summarized in Table 1 . There is significant difference in gender and racial distribution between HCP and parents $(p<0.001)$. HCP are predominantly female and multi-racial. There is no statistical significance between neurotypical and SDF children with regards to the baseline characteristics.

\section{Functionality of I-MOVE}

Parent and HCP group perception on the functionality of I-move is summarized in Figure 2. Twenty-nine parents $(96.7 \%)$ opined that such a system would lead to a better management of combative children (12 Strongly agree, 13 agree, 4 more or less agree). All HCP found the menu control for operations of the multi-positional transformation easy to use.

\section{General Acceptance of I-MOVE}

Comparison of parental and Child's opinion on general experience is shown in Figure 3.

\section{Situational use of I-MOVE}

Use of IMOVE in within hospital transport of children is endorsed by $\operatorname{HCP}(n=32,100 \%)$ and parents $(n=29,96.7 \%)$; induction of anaesthesia for neurotypical children by $\operatorname{HCP}(n=32,100 \%)$ and parents $(n=28,93.3 \%)$. In addition, use of IMOVE is indicated by children for induction of anaesthesia $(n=22$, $95.7 \%)$, induction of sleep $(n=17,73.9 \%)$, dental check-up $(n=19,82.6 \%)$ and dental check-up $(n=19$, $82.6 \%)$.

\section{Use of restraint on children}

Twenty-four parents agree to using restraint as long as it is needed for care and treatment. Ten parents agreed as long as it is necessary for their child's safety. Five parents agreed as long as they feel that their 
child is not physically hurt, 2 parents agreed if they feel their child is not upset while 1 parent is agreeable if he/she was not upset by the restraint. One parent did not agree for restraint use under any circumstance; the same parent however opined that he did not object to the use of 'restraint module' of IMOVE as he felt that the restraint module provides safe securing of the child rather than restraining a child.

Free response on likes and dislikes of parents are summarized in Table 2 and 3 with supporting quotations. Quotations incorporated four subthemes of likes that were common in both parent and child group, these were related to attractiveness, functionality, safety, comfort of use of I-MOVE. In addition, ease of use ( $n=2)$ and innovative design ( $n=2)$ was identified in the parent group, while 3 children responded that they are happy to be in it. Subthemes relating to dislikes are presented in Table 3.

\section{Discussion}

The design of I-MOVE focuses on both functionality and external appeal; Essential functionality includes ability to restraint and to assist movement and transfer of children through enabling multi-position transformation of the mobility device. The aim is to improve patient safety, increase efficiency and reduce perioperative staff injury during patient transfer to operating room, induction of anaesthesia and transfer to the operating table. The external appeal of the mobility device aims to promote positive child-machine interaction and enhance patient experience. Here, the seat module of I-MOVE bears likeness to various forms of a chair (racing chair in sitting configuration, recliner massage chair when supine) and the restraint modules resembles those found in airplanes and amusement rides. By integrating elements of familiarity and fun with functionality, we hope to achieve reduction of stress and anxiety and greater acceptance of the mobility device by children.

In recent years, greater understanding and awareness of ASD had led to efforts to optimize management of ASD children in the hospital environment for a better patient experience. At the same time, there has been a paradigm shift towards evidence-based practice in patient handing equipment focusing on ergonomics [14]. The act of transferring patients on and off OR beds has also been identified by the Association of periOperative Registered Nurses Workplace Safety Task Force as a high-risk task for healthcare staff musculoskeletal injury in the perioperative area [15]. Standards relating to safe patient handling and injury prevention now recommend the use of engineering control to perform lifting, transferring and repositioning of patients and eliminating manual lifting of patients when the load exceeds 35 pounds [16].

Anxiety and disruptive behaviour requiring sedation for children with ASD are common in the preoperative period, reported sedation rates in studies ranged from $76 \%-87.5 \%[17,18,19]$. In our hospital, sedation is administered to the patient in the OT waiting area if deemed necessary by the attending anaesthesiologists. After which, the patient waits on a trolley before transfer to the OR. Children who do not require sedation either walk or travel on a trolley, wheelchair or a pull cart to the OR. Parental presence in the OR at induction of anaesthesia is the standard practice. For children who refuse to sit on the 
operating table, they are placed on parents' lap during inhalation induction, then lifted and carried onto the operating table by healthcare staff after being anaesthetised. When child becomes anxious and noncompliant, these movements may become difficult, require manpower to hold and restraint, and may put patient at risk of injury during fight or flight. Manual transfer of child from parent's lap to operating table may also predispose a child to fall risk especially when child is older and heavier.

Vast majority of parents and HCP opine favourably for the use of I-MOVE system concept to improve the management of perioperative movement $(90.0 \%$ parents, $100 \% \mathrm{HCP})$ and to enable safe perioperative movement of children ( $86.7 \%$ parents, $96.9 \% \mathrm{HCP}$ ) in the situation when children becomes uncooperative. Among the experts, $90.6 \% \mathrm{HCP}$ and $76.7 \%$ of parents would recommend frequent use of such a system on combative ASD children while more (93.8\% HCP, $86.7 \%$ parents) would recommend the system to others (HCP and parents). We have recruited perioperative HCP and parents in the evaluation of the concept mobility device for two reasons. HCP are clinical expert in management of ASD children in the perioperative process and gives valuable practical input while parents are content experts in the care of ASD children and the best resource for developing individualized strategies for a successful experience [8]. The opinion between HCP and parents on the functionality of the system is not dissimilar, though parental ratings are more conservative. Comfort of anaesthesia and ease of induction of anaesthesia were two domains that were rated the lowest by parents $(76.7 \%$ agree or strongly agree) and are areas to improve and explore in future.

Parents and children are found to share similar reasons for their likes and dislikes for the mobility device, namely attractiveness, fun and functionality. Most children did not find the restraint module intimidating as the design inspires fun (amusement park) and gives the perception of protective stabilization rather than a forceful lock-down. Most parents are also accepting to the use of restraint if it is required for treatment and if applied in a secure and safe manner. Children's endorsement for use of I-MOVE to 'go to sleep' for surgery is lower than its use as dental chair, it is not known if the notion of 'surgery' had negatively impacted the children's opinion, this can be evaluated in future.

There are inherent limitations in this study. Firstly, this is a proof of concept, the evaluation is not based on bed-side use. Active participation from the children in I-MOVE in a non-clinical environment. Secondly, the ASD cohort in our study are cognitively abled while general population of ASD children are known to have intellectual and learning abilities [20]. Severe ASD patients are often the group that require physical restraint [21] and is our population of interest. Our findings may not be generalized to those with severe behaviour problem or those who turn combative or develop aggression during the perioperative period or to clinical setting at this juncture. Lastly, we have included neurotypical children because deployment of system in practice will be extended to all children.

This is one of the first studies that report on perioperative movement of children with ASD. Currently there is no standardized strategies or guidelines for safe transportation targeted exclusively for the perioperative period. This proof of concept work represents a multidisciplinary collaborative approach between HCP, engineers and parents to create an approach to improve the perioperative journey. Early 
introduction of I-MOVE early such as during surgery consult or integration of I-MOVE into a social story can help familiarize the children with the concept of I-MOVE for hospital mobility. It may be worthwhile to explore the use of I-MOVE for intra-hospital transfer outside the OT environment for ASD children to gather clinical use experience.

\section{Conclusion}

A concept mobility device that integrates appeal for child-machine interaction through context of familiarity and fun with functionality of restraint and multi-positional transformation, was opined by vast majority of HCP and parents of ASD children to promote safe movement and induction of anaesthesia in anxious ASD children.

\section{Declarations}

\section{Ethics approval/ consent to participate/ Consent for publication}

Ethics approval and consent were obtained. See Methodology. The manuscript does not contain any individual person's data.

\section{Availability of data and materials}

The datasets used and/or analysed during the current study are available from the corresponding author on reasonable request. All data generated or analysed during this study are included in this published article.

\section{Competing interests}

A patent 'A personal transportation apparatus' was filed on 22 Jan 2018. 2019-07025. Application Number 10201800576V, eFile ref number: E201801220392T. Publication was on https://patents.google.com/patent/W02019143301A1.The above patent was abandoned on 11 May 2020 before its National phase due on 22 July 2020.

The authors declare no current conflict of interest as the patent filing has been abandoned. The sponsors had no role in design, execution, interpretation or writing of the study

\section{Funding}

The development of the prototypes was funded by the National Research Foundation, Singapore (NRF2015NRF-POC001-051); Robotic actuated specialized motorized vehicle for perioperative management of uncooperative combative special needs children-multifunctional modalities for transport, transfer and procedures).

\section{Authors' contributions}


$\mathrm{HIH}$ : Concept of specialized mobility device, conception and design of the survey, data collection, data analysis and interpretation, drafting the manuscript, critical revision of drafts. YCL : Patient screening, enrolment, recruitment, critical review of draft. TT: Patient recruitment, data collection, review of draft. SW: Patient recruitment, data collection, review of draft. OW: Patient recruitment, data collection, review of draft. SL: Patient recruitment, data collection, critical review of draft. KR: Concept of specialized mobility device, critical revision of draft for intellectual content.

\section{Acknowledgements}

We thank Major Operating theatre and Day surgery, KK Women's and Children's Hospital for the support and assistance in the project. The development of the prototypes was funded by the National Research Foundation, Singapore (NRF2015NRF-P0C001-051; Robotic actuated specialized motorized vehicle for perioperative management of uncooperative combative special needs children-multifunctional modalities for transport, transfer and procedures). We thank KL Ng, M STA Cruz, A Tan from HOPE Technik, Singapore and HY Yu from national University Singapore for the collaboration in development of the prototypes.

\section{References}

1. Vlassakova BG, Emmanouil DE. Perioperative considerations in children with autism spectrum disorder. Curr Opin Anaesthesiol. 2016;29:359-366. doi:10.1097/AC0.0000000000000325

2. Lord C, Elsabbagh M, Baird G, Veenstra-Vanderweele. J. Autism spectrum disorder. Lancet. 2018;392:508-520. doi:10.1016/S0140-6736(18)31129-2

3. Povey C. Helping children on the autism spectrum deal with hospital admissions. Arch Dis Child. 2016;101:1081. doi:10.1136/archdischild-2016-311299 (e2)

4. Taghizadeh N, Davidson A, Williams K, Story D. Autism spectrum disorder (ASD) and its perioperative management. Paediatr Anaesth. 2015;25:1076-1084. doi:10.1111/pan.12732

5. Al Sharif S, Ratnapalan S. Managing Children With Autism Spectrum Disorders in Emergency Departments. Pediatr Emerg Care. 2016;32:101-103. doi:10.1097/PEC.0000000000000705

6. Bhat AN, Landa RJ, Galloway JC. Current perspectives on motor functioning in infants, children, and adults with autism spectrum disorders. Phys Ther. 2011;91:1116-1129. doi:10.2522/ptj.20100294

7. McManus BM, Prosser LA, Gannotti ME. Which Children Are Not Getting Their Needs for Therapy or Mobility Aids Met? Data From the 2009-2010 National Survey of Children With Special Health Care Needs. Phys Ther. 2016;96:222-231.

8. Thompson DG, Tielsch-Goddard A. Improving management of patients with autism spectrum disorder having scheduled surgery: optimizing practice. J Pediatr Health Care. 2014;28:394-403. doi:10.1016/j.pedhc.2013.09.007

9. O'Neil J, Hoffman B; COUNCIL ON INJURY, VIOLENCE, AND POISON PREVENTION. Transporting Children With Special Health Care Needs. Pediatrics. 2019;143:e20190724. doi:10.1542/peds.2019- 
0724

10. O'Neil J, Hoffman BD; COUNCIL ON INJURY, VIOLENCE, AND POISON PREVENTION. School Bus Transportation of Children With Special Health Care Needs [published correction appears in Pediatrics. 2018 Jul;142.

11. Hee HI, Raghavan K, Tan A, Ng KL, Cruz MS, Yu H. Enhancing perioperative transfer of special needs children with the I-MOVE 2017 IEEE International Conference on Cybernetics and Intelligent Systems (CIS) and IEEE Conference on Robotics, Automation and Mechatronics (RAM), Ningbo, 2017, pp. 530534, doi: 10.1109/ICCIS.2017.8274832.

12. Hee Ng KL, Cruz MS, Tan A, Yu H. IMOVE-An Intuitive Concept Mobility Systems for Perioperative Transfer and Induction of Anaesthesia for Special Needs Children. Sensors (Basel). 2020;20(17):E4901. Published 2020 Aug 30. doi:10.3390/s20174901

13. https://patents.google.com/patent/WO2019143301A1. A personal transportation apparatus. InventorHwan Ing HEEHaoyong Yu. Accessed 4 June 2020.

14. Cantrell S. Ergonomics, engineering engender safe patient handling and lifting Healthcare Purchasing News. 2013; 37, 5; Business Premium Collection pg. 20

15. Link T. Guideline Implementation: Safe Patient Handling and Movement: 1.8 www.aornjournal.org/content/cme. AORN J. 2018;108:663-674. doi:10.1002/aorn.12423

16. Motacki K, Motacki LM. Safe patient handling and movement in a pediatric setting. Pediatr Nurs. 2009;35:221-225.

17. Van der Walt JH1, Moran C. An audit of perioperative management of autistic children. Paediatr Anaesth. $2001 \mathrm{Jul} ; 11: 401-8$.

18. Arnold B, Elliott A, Laohamroonvorapongse D, Hanna J, Norvell D, Koh J. Autistic children and anesthesia: is their perioperative experience different? Paediatr Anaesth. 2015 Nov;25:1103-10. doi: 10.1111/pan.12739. Epub 2015 Sep 4.

19. Elliott AB, Holley AL, Ross AC, Soleta AO, Koh JL. A prospective study comparing perioperative anxiety and posthospital behavior in children with autism spectrum disorder vs typically developing children undergoing outpatient surgery. Paediatr Anaesth. 2018 Feb;28:142-148. doi:

10.1111/pan.13298. Epub 2017 Dec 10.

20. Vaz I. Improving the management of children with learning disability and autism spectrum disorder when they attend hospital. Child Care Health Dev. 2010;36:753-755. doi:10.1111/j.13652214.2010.01144.x

21. Johnson NL, Rodriguez D. Children with autism spectrum disorder at a pediatric hospital: a systematic review of the literature. Pediatr Nurs. 2013;39:131-141.

\section{Tables}

Table 1. Baseline characteristics of participants

GA; general anaesthesia, OTTA; operating theatre assistant 


\begin{tabular}{|c|c|c|c|}
\hline & $\begin{array}{l}\mathrm{HCP} \\
\mathrm{N}=32\end{array}$ & \multicolumn{2}{|l|}{$\begin{array}{l}\text { Parents } \\
\mathrm{N}=30\end{array}$} \\
\hline Age in years, mean (SD) & $39.66(10.62)$ & \multicolumn{2}{|l|}{$43.9(4.73)$} \\
\hline \multicolumn{4}{|l|}{ Gender, N (\%) Male: Female } \\
\hline $\begin{array}{l}\text { Race, N (\%) Chinese: Malay: } \\
\text { Indian: Others }\end{array}$ & 3(9.38): 29(90.63) & \multicolumn{2}{|c|}{ 10(33.3):20(66.7) } \\
\hline $\begin{array}{l}\text { Years of work experience, mean } \\
\text { (SD) }\end{array}$ & 18:1:0:13 & \multicolumn{2}{|l|}{$23: 1: 6: 0$} \\
\hline \multicolumn{4}{|l|}{$\begin{array}{l}\text { Job scope, N (\%) : Nurse: Doctor: } \\
\text { OTA }\end{array}$} \\
\hline \multirow{5}{*}{ GA experience, $N(\%)$} & 25(78.13):6(18.8):1(3.12) & \multicolumn{2}{|l|}{ NA } \\
\hline & $32(100.0)$ & \multicolumn{2}{|l|}{ 13(43.3) } \\
\hline & Neurotypical & ASD & All Children \\
\hline & Children & Children & $\mathrm{N}=23$ \\
\hline & $N=9$ & \multicolumn{2}{|l|}{$N=14$} \\
\hline Age in years, mean (SD) & 10.61(3.28) & $9.82(1.44)$ & $10.12(2.30)$ \\
\hline Gender, N (\%) Male: Female & 4(44.4): 5(55.6) & \multirow{2}{*}{$\begin{array}{l}\text { 11(78.6): } \\
3(21.4)\end{array}$} & \multirow{2}{*}{$\begin{array}{l}\text { 15(65.22): } \\
8(34.78)\end{array}$} \\
\hline History of previous GA experience, & $2(25.0)$ & & \\
\hline$N(\%)$ & $6(1.41)$ & $8(57.1)$ & 19:0:4:0 \\
\hline Years since last GA, mean (SD) & $3711(1663)$ & $6.25(3.01)$ & $6.20(2.70)$ \\
\hline Weight in kg, mean (SD) & (10.00) & $37.06(11.08)$ & $37.08(2.70)$ \\
\hline Height in kg, mean (SD) & $144.09(10.04)$ & $141.89(9.84)$ & $143.07(12.28)$ \\
\hline
\end{tabular}

Table 2. Summary of what parent and children like about I-MOVE system 


\section{What Parents like}

1. Attractiveness $(\mathbf{n}=\mathbf{1 4})$. Design, shape, colours are appealing and attractive and sporty(for boys)

.'The device resembles amusement park ride, rollercoaster, Virtual Reality chair, arcade (game) chair, office chair'. 'chair' design is familiar, children can relate to it easily and has less anxiety and hence not intimated by the device.' 'Looks like children are going on a ride, makes it easier to get them on it'. 'The relationship associated with fun in using the chair makes its use less intimidating to children'.

2. Functionality $(\boldsymbol{n}=14)$. The multifunction and flexibility in usage related to the multi-positional features, its automated design and foot rest. The chair design and restraint ensure safe movement. 2 parents cited ease of use.

Useful in 'movement between different floors during hospital transfer', 'holding children in dental chair' " transfer to the OT table and movement in the perioperative period', making 'handling of child smoother'. 'Less chance of injury during transfer', 'can replace wheelchair'.

\section{Safety_( $(\mathbf{n = 9})$. The structure and restraint feature.}

The device design ensures 'safety precaution and is able to control child with safety feeling'. 'Over the head chest harness (resembling a seat on roller coaster rides) is a good safety feature for holding children's head safely during moving after sedation. 'Looks sturdy for heavy kids. 'very helpful for ASD patients towards mobility safety measures and concerns.'

\section{Comfort $(\underline{n=4})$. Comfortable.}

'does not look cold or intimidating'. Its 'bright colours also comforting to the child to sit on it'.

\section{What children like}

1. Attractiveness ( $n=15)$. Chair and the amusement park restraint design are described as cool/nice/ high tech/ interesting//colourful.

'The restraint/handle and colour are cool', 'like a massage chair or a roller coaster'. 'it is full of colours, I like it but don't know why, I want to use the chair'. 'chair is cool and makes me feel like it would not be a serious operation'.

1. Functionality ( $(\mathbf{n}=9)$. The ability to move and transform into various shapes and forms for difference uses and ability to hold children with remote control.

I like the moving thing about it and that it can move with remote control and can sleep on chair. 'the chair is versatile and solving many problem'. 'If child is afraid and wants to run away seatbelt can hold them'. 'I like to go to sleep for operation in this chair, Like to sit on it, go round and round in it'.

\section{Safety and security $(\underline{n=4})$.}

'Especially important for a child who is unsure if what is going to happen'. 'It is safer to carry child'.

\section{Comfortable $(\underline{n=8})$.}

'comfortable', 'Like the speed', 'feels happy and like to sit'.

\section{Innovative and creative $(n=2)$.}

Table 3. Summary of what parent and children dislike about I-MOVE system

*Despite the seat belt being adjustable, children find it hard to do so 


\section{What parents did not like}

1. None $(\underline{n=5})$.

2. Restrain $(\underline{n=9})$. (a) mechanism of the seat belt buckle $(n=4)$ (b) design of overhead chest restraint $(n=3)$. Inadequate restraint $(n=2)$.

Input include 'seat belt not easy to 'lock and unlock', 'place the seat belt buckle at the back so that the child could not unbuckle themselves', use a '4 points seat-belt', use 'auto lock over-head chest restraint', 'overhead restraint looks intimidating, may get in the way of tall child'. Add 'more restraints, such as seat belt around the leg, is useful when child is unable to keep their arms to themselves'.

1. Colour $(\underline{n=6})$. The current colours (black and red) may not appeal to all children.

Input include 'red colour may appear dangerous and intimidating'. 'colours may not be appealing for girls.' Calming colours (like blue), dim shades of colour or more cheerful and happy colours'.

\section{Motor Sound $(n=4)$.}

2. Comfort $(n=3)$ relating to the seat cushion.

'The head pillow was at a fixed position and could not be removed for more comfort'. "Not sure if the pillow is comfortable"

1. Others $(\mathbf{n}=2)$. 'Device appears too attractive that the child may think it is a computer game chair and is expecting to have some sort of game play'. 'The bucket seat appears to be like a race car too fast too furious'.
What children did not

like

1. None ( $n=6)$.

2. Seat belt restraint (n=6). Concern range from hard to apply, uncomfortable and tight for the bigger child*.

3. Colour of the chair seat $(n=2)$.

'Red is too bright'. 'Suggest black', 'Colour is a bit fierce'

\section{Motor Sound (n=2).}

2. Size $(\underline{n=3})$.

'The device is big and the head pillow is too high $(9,11$ years old $)$

\section{Movement $(n=2)$.}

children may find it 'scary' when chair moves up for those fearful of height' and 'if they think that no one is controlling the chair.

\section{Figures}




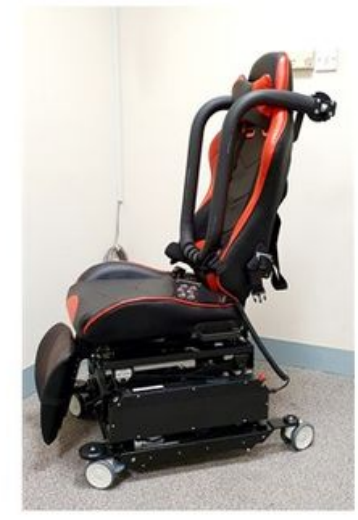

$1 \mathrm{a}$

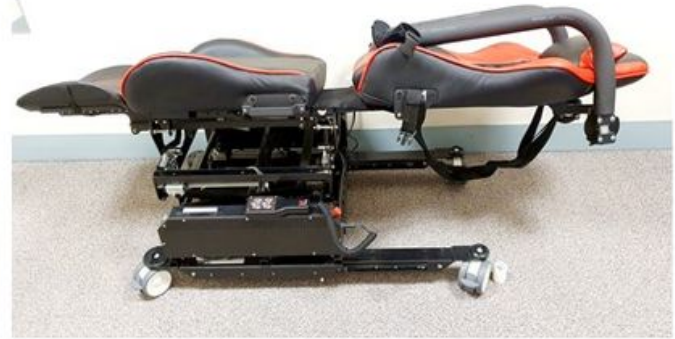

$1 b$

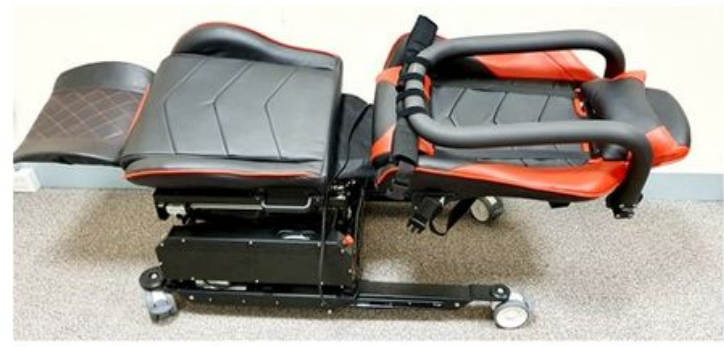

1c

\section{Figure 1}

Illustration of the Specialized Apparatus for Transport, I-MOVE in (a) sitting position (b) supine position (c) lateral tilt

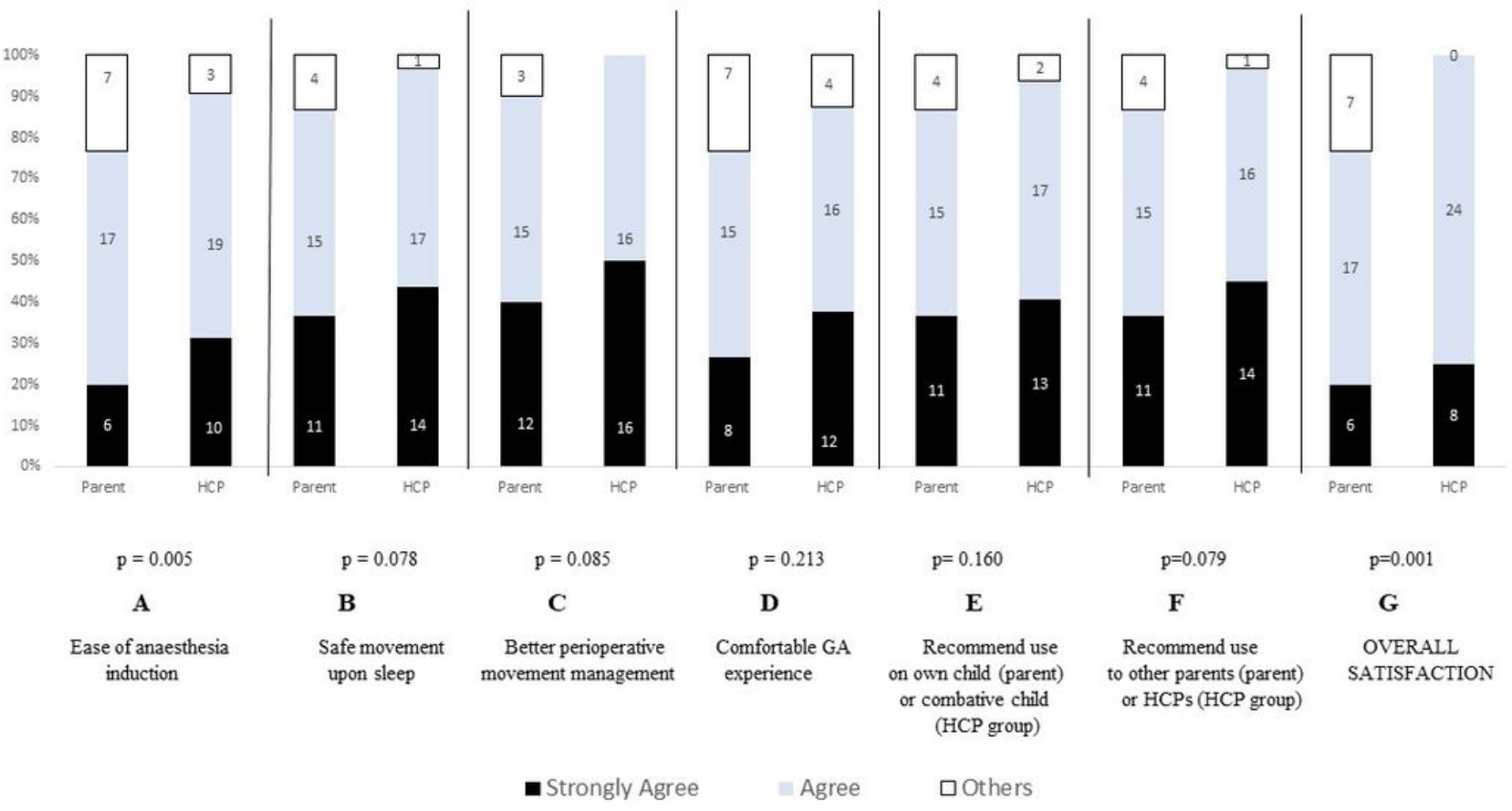


Figure 2

Comparison between HCP and parents on rating on functionality of the I-MOVE. GA; general anaesthesia. Others include rating of More or less agree, undecided, more or less disagree, disagree and strongly disagree

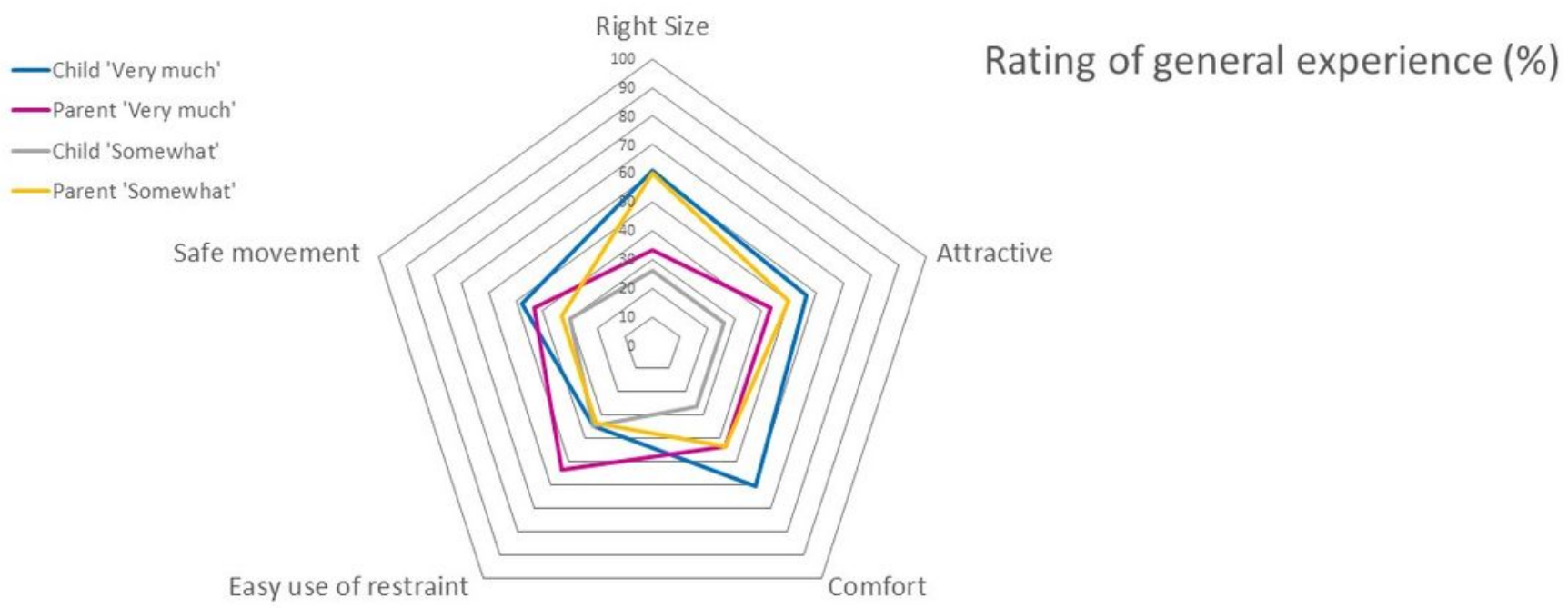

\begin{tabular}{llllll}
\hline Responses, N(\%) & Right size & Attractive & Comfortable & Restraint easy to use & Safe movement \\
\hline Undecided, Child: parent & $2(8.7): 1(3.3)$ & $3(13.0): 2(6.7)$ & $3(13.0): 0(0.0)$ & $4(17.4): 2(6.7)$ & $4(17.4): 2(6.7)$ \\
Not really, Child: parent & $1(4.3): 1(3.3)$ & $1(4.3): 0(0.0)$ & $0(0.0): 1(3.3)$ & $1(4.3): 0(0.0)$ & $0(0.0): 1(3.3)$ \\
Not at all, Child: parent & $0(0.0): 0(0.0)$ & $0(0.0): 0(0.0)$ & $0(0.0): 0(0.0)$ & $2(8.7): 1(3.3)$ & $0(0.0): 0(0.0)$ \\
\hline
\end{tabular}

\section{Figure 3}

Comparison between parents and children on overall experience of I-MOVE. 